\title{
Sensitivity to chemotherapeutics of NSCLC cells with acquired resistance to EGFR-TKIs is mediated by T790M mutation or epithelial-mesenchymal transition
}

\author{
JUAN ZHOU* ${ }^{*}$, QIAOTING HU* ${ }^{*}$ XI ZHANG ${ }^{*}$, JIHUA ZHENG, BO XIE, ZHIYONG XU and WEIMIN ZHANG \\ Department of Oncology, The General Hospital of Guangzhou Military Command of The People's Liberation Army (PLA), \\ Guangzhou, Guangdong 510010, P.R. China
}

Received June 24, 2017; Accepted January 26, 2018

DOI: $10.3892 /$ or.2018.6242

\begin{abstract}
Chemotherapy is one of the methods to treat patients with non-small cell lung cancer (NSCLC) developing resistance to epidermal growth factor receptor (EGFR) tyrosine kinase inhibitors (TKIs), such as gefitinib. Previous studies revealed that the sensitivity to chemotherapy may depend on different cellular mechanisms of acquired EGFR-TKIs resistance. Thus, the present study aimed to investigate the sensitivity of distinct gefitinib-resistant NSCLC cell lines to chemotherapy in order to help select effective treatment regimens for patients with EGFR-TKI resistance. In the present study, we established two gefitinib-resistant cell lines (PC-9/ZD and PC-9/GR) with the human lung adenocarcinoma cell line PC-9 (carrying the delE746-A750 mutation in the EGFR gene). PC-9/ZD cell line expressed the T790M mutation, while PC-9/GR presented the phenotypes of epithelial to mesenchymal transition (EMT). PC-9/ZD cells were more sensitive to paclitaxel and docetaxel than PC-9 cells and knockdown of T790M decreased this sensitivity. In addition, PC-9/GR cells were less sensitive to chemotherapeutic drugs tested, including cisplatin, gemcitabine, pemetrexed, paclitaxel and docetaxel, compared to PC-9 and PC-9/ZD cells. CDH1 transfection reversed the EMT and restored the sensitivity to chemotherapy in PC-9/GR cells. Furthermore, PC-9 cells became resistant to chemotherapy after TGF- $\beta 1$-induced EMT. The EMT in NSCLC cells significantly increased cancer stem cell (CSC) properties and tumorgenicity. Collectively, the present study revealed that
\end{abstract}

Correspondence to: Dr Weimin Zhang, Department of Oncology, The General Hospital of Guangzhou Military Command of The People's Liberation Army (PLA), 111 Liuhua Road, Guangzhou, Guangdong 510010, P.R. China

E-mail: wmzhang79@126.com

${ }^{*}$ Contributed equally

Key words: T790M, epithelial-mesenchymal transition, epidermal growth factor receptor-tyrosine kinase inhibitors, non-small cell lung cancer, drug resistance gefitinib-resistant NSCLC cells carrying the T790M mutation were sensitive to taxane chemotherapy, indicating that T790M is a useful biomarker for the selection of chemotherapy. EMT in NSCLC cells confers resistance to chemotherapy, which may be associated with enhanced CSC properties.

\section{Introduction}

The majority (80-85\%) of lung cancers are non-small cell lung cancer (NSCLC), which is the leading cause of cancerrelated death (1). Epidermal growth factor receptor (EGFR) with primary gain-of-function mutations is a major molecular driver of NSCLC. EGFR-tyrosine kinase inhibitors (EGFRTKIs), such as gefitinib and erlotinib, have been effective standard therapies for NSCLC with EGFR mutations. However, almost all patients with NSCLC develop drug resistance to EGFR-TKIs $(1,2)$.

Multiple mechanisms underlying the resistance to EGFRTKIs in NSCLC have been identified. These mechanisms include the T790M mutation (a threonine to methionine mutation in amino acid 790), c-MET amplification, activation of alternative signaling pathways and epithelial to mesenchymal transition (EMT) (1). EMT refers to epithelial cell transformation, loss of epithelial characteristics and morphological transformation to a stromal cell phenotype. Biochemically, EMT is characterized by the reduction of E-cadherin and the induction of vimentin (2). EMT is also an important mechanism in the acquired resistance (AR) to EGFR-TKIs. EMT is detected in $\sim 5 \%$ of patients with secondary resistance to EGFR-TKIs (3).

Much effort has been directed toward overcoming the AR to EGFR-TKIs by targeting specific mechanisms of resistance. AZD9291 has been used to treat patients with AR to EGFRTKIs with the T790M mutation. However, $50 \%$ of patients with AR to EGFR-TKIs without the T790M mutation need subsequent chemotherapy and predictive clinical factors to determine sensitivity to chemotherapy for these patients are still lacking $(1,4)$.

Previous studies have revealed that chemotherapy efficacy may depend on the underlying mechanisms of AR to EGFR-TKIs. Rosell et al (5) observed that in patients with secondary T790M, tumors were more sensitive to 
chemotherapeutic drugs, thus prolonging progression-free survival (PFS) and overall survival (OS). In contrast, NSCLC cells with EMT and patients with EMT-positive tumors were less sensitive to chemotherapy or radiotherapy (6). Furthermore, Kuo et al (4), revealed that in patients with AR to EGFR-TKIs, PFS and OS were improved by taxanes, although the underlying mechanisms of EGFR-TKI resistance are unknown (4).

PC-9 is a NSCLC cell line sensitive to gefitinib. PC-9 cells have an EGFR-activating mutation, which is a 15-bp deletion in the EGFR exon 19 (7). In the present study, we used two PC-9 sublines, PC-9/ZD and PC-9/GR, which achieve AR through a secondary T790M mutation and development of EMT, respectively. We studied the correlation between sensitivity of NSCLC cells to chemotherapeutic drugs and different mechanisms of EGFR-TKI resistance. We revealed that the T790M mutation increased NSCLC sensitivity to chemotherapy, whereas EMT resulted in the opposite effect. Furthermore, we observed that EMT led to chemotherapeutic resistance by enhancing cancer stem cell (CSC) properties.

\section{Materials and methods}

Cell culture and NSCLC sublines with AR to EGFR-TKIs. The human lung adenocarcinoma cell line PC-9 (carrying the delE746-A750 mutation in the EGFR gene) was purchased from The Shanghai Cell Collections of the Chinese Academy of Sciences (Shanghai, China). The gefitinib-resistant subline PC-9/ZD was donated by Dr Koizumi at the National Cancer Center Hospital (Tokyo, Japan). The gefitinib-resistant PC-9/GR subline was generated as previously described (7). The cancer cells were cultured in RPMI-1640 supplemented with $10 \%$ fetal bovine serum (FBS) (both from Sigma-Aldrich, St. Louis, $\mathrm{MO}, \mathrm{USA})$ at $37^{\circ} \mathrm{C}$ and $5 \% \mathrm{CO}_{2}$.

Analysis of the EGFR gene mutations and c-METamplification. DNA was prepared from cancer cells using the High Pure PCR Template Preparation kit (Roche Molecular Biochemicals, Indianapolis, IN, USA) according to the manufacturer's instructions. We used the amplification refractory mutation system (ARMS) kit (Zhensheng Biomed, Xiamen, China) to detect point mutations in the EGFR gene in exons 18, 19, 20 and 21. Amplification of c-MET was determined by fluorescence in situ hybridization (FISH) as previously described (7).

Cell Counting Kit-8 (CCK-8) cell viability assay. Cells in logarithmic growth phase were inoculated into 96 -well plates at a density of $1.5 \times 10^{3}$ cells/well. After attachment, the cells were treated with different concentrations of various drugs. The drugs tested included gefitinib $\left(10^{-2}-10^{2} \mu \mathrm{mol} / \mathrm{l}\right)$, paclitaxel $\left(10^{-4}-10^{4} \mathrm{nmol} / \mathrm{l}\right)$, docetaxel $\left(10^{-4}-10^{4} \mathrm{nmol} / \mathrm{l}\right)$, pemetrexed $\left(10^{-4}-10^{4} \mathrm{nmol} / \mathrm{l}\right)$, cisplatin $\left(10^{-2}-10^{2} \mu \mathrm{mol} / \mathrm{l}\right)$ and gemcitabine $\left(10^{-4}-10^{4} \mathrm{nmol} / \mathrm{l}\right)$ (Sigma-Aldrich). After $72 \mathrm{~h}$, cell viability in each well was determined using the CCK-8 kit (Dojindo Laboratories, Kumamoto, Japan) according to the manufacturer's instructions.

\section{In vitro cell migration and invasion assays}

Scratch wound assay. Cells at a logarithmic growth phase were inoculated in 12-well plates at $5.0 \times 10^{4}$ cells/well. After reaching $80 \%$ confluency, the cells were starved overnight in serum-free medium. Pipette tips $(10 \mu \mathrm{l})$ were used to generate three scratch lines in parallel in the cell monolayer. Images were captured at $0,12,24$ and $48 \mathrm{~h}$ post wound under a phase-contrast microscope (Olympus, Tokyo, Japan). Each experiment was repeated at least three times.

Invasion assays. $\mathrm{QCM}^{\mathrm{TM}}$ 24-well Collagen-based Cell Invasion assay Transwell plates (EMD Millipore, Darmstadt, Germany) were used for invasion studies. Cells $\left(5 \times 10^{5}\right)$ were suspended in $200 \mu \mathrm{l}$ of serum-free medium and added to the upper chamber. RPMI-1640 medium (500 $\mu$ l) containing 10\% newborn bovine serum was added to the lower chamber as a chemokine attractant. The cells that migrated into the lower chamber were stained with crystal violet for $30 \mathrm{~min}$. Five fields per chamber were imaged using an Olympus fluorescence inverted microscope (Olympus).

Western blot analysis. Equal amounts of total protein were resolved by SDS-PAGE and blotted onto polyvinylidene fluoride (PVDF) membranes. The membranes were probed with primary antibodies against vimentin $(1: 1,500$; no. SAB1305445), E-cadherin (1:1,000; no. SAB5500022), EGFR (1:1,000; no. SAB4300352), phosphorylated (p)EGFR (1:1,000; no. SAB4503760), AKT (1:1,000; no. SAB4500802), pAKT (1:1,000; no. SAB4504015), extracellular regulated kinase (ERK; 1:1,000; no. M5670), pERK (1:1,000; no. SAB4301578) and $\beta$-actin (1:400; no. SAB5500001) (all antibodies were rabbit anti-human monoclonal and were purchased from Sigma-Aldrich). After incubation with primary antibodies for $24 \mathrm{~h}$, the blots were incubated with HRP-conjugated secondary antibody (1:2,000; no. A9169, goat anti-rabbit polyclonal antibody; Sigma-Aldrich). Protein band intensity was analyzed using Quantity One image analysis software (Bio-Rad Laboratories, Hercules, CA, USA).

STable expression of E-cadherin and EGFR T790M-specific siRNA by lentiviral transfection. STable overexpression of cadherin 1 (CDH1) and T790M-specific siRNA was performed as previously described (7). Four T790M specific siRNA sequences $(2608,2597,2603$ and 2600) described by Chen et al (8) were used to identify the best sequence to interfere with the expression of T790M, but minimally affect the expression of wild-type (WT) EGFR for further studies. The negative shRNA sequence was LV3-NC: 5'TTCTCCGAA CGTGTCACGTTTC 3 '.

Real-time PCR was employed to determine the expression level of EGFR mRNA using the following oligonucleotides: EGFR forward and EGFR reverse for the WT allele (9) and T790M forward, 5'TCCTCGATGAAGCCTACGTGAT3' and reverse, 5'CAAGCGACGGTCCTCCAAGTAG3' (10).

CSC analysis. The expression of CD133 and CD44, putative biomarkers for the NSCLC CSCs was determined by flow cytometry. Cells $\left(10^{6}\right)$ collected in a $1.5 \mathrm{ml}$ EP tube were incubated with $100 \mu \mathrm{l}$ diluted fluorescent-conjugated antibodies against CD133 and CD44 (both from BD Biosciences, Franklin Lakes, NJ, USA), or in a control group with $100 \mu \mathrm{l}$ phosphate buffered solutions with albumin (PBA), on ice for $1 \mathrm{~h}$ in the dark. The cells were then washed three times with (PBS). Following centrifugation $\left(600 \mathrm{xg}, 4^{\circ} \mathrm{C}, 10 \mathrm{~min}\right)$, the precipitated 
Table I. IC $_{50}$ values of various chemotherapeutic agents in NSCLCs with AR to EGFR-TKIs.

\begin{tabular}{lcrr}
\hline $\mathrm{IC}_{50}$ & PC-9 & PC-9/GR & PC-9/ZD \\
\hline Cisplatin $(\mu \mathrm{mol} / \mathrm{l})$ & $3.877 \pm 1.346$ & $20.283 \pm 4.316^{\mathrm{a}}$ & $2.956 \pm 1.685^{\mathrm{b}}$ \\
Gemcitabine $(\mu \mathrm{mol} / \mathrm{l})$ & $0.145 \pm 0.724$ & $2.647 \pm 0.117^{\mathrm{a}}$ & $0.130 \pm 0.028^{\mathrm{b}}$ \\
Pemetrexed $(\mu \mathrm{mol} / \mathrm{l})$ & $30.517 \pm 4.69$ & $399.530 \pm 0.903^{\mathrm{a}}$ & $36.100 \pm 4.615^{\mathrm{b}}$ \\
Paclitaxel $(\mathrm{nmol} / \mathrm{l})$ & $1.532 \pm 0.777$ & $16.710 \pm 4.023^{\mathrm{a}}$ & $0.124 \pm 0.231^{\mathrm{a}, \mathrm{b}}$ \\
Docetaxel $(\mathrm{nmol} / \mathrm{l})$ & $5.226 \pm 0.648$ & $64.560 \pm 8.454^{\mathrm{a}}$ & $0.800 \pm 0.109^{\mathrm{a}, \mathrm{b}}$ \\
\hline
\end{tabular}

${ }^{\mathrm{a}}$ Indicates statistically significant difference from the $\mathrm{IC}_{50}$ values in PC-9 cells $(\mathrm{P}<0.05)$; bindicates statistically significant difference from the $\mathrm{IC}_{50}$ values in PC-9/GR cells. IC 50 , inhibitory concentrations at 50\%; NSCLC, non-small cell lung cancer; AR, acquired resistance; EGFR-TKIs, epidermal growth factor receptor-tyrosine kinase inhibitors.

cells were re-suspended in $300 \mu \mathrm{l} \mathrm{PBS}$, followed by flow cytometric analysis (BD, Biosciences, Franklin Lakes, NJ, USA).

Side population assay. Cells $\left(10^{6}\right)$ were incubated with (test group) or without (control group) $50 \mu \mathrm{mol} / 1$ verapamil. Hoechst 33342 (Sigma-Aldrich) was added to a final concentration of $5 \mu \mathrm{g} / \mathrm{ml}$ followed by addition of pyridine iodide at a final concentration of $2 \mu \mathrm{g} / \mathrm{ml}$ to screen for dead cells. The cells were then subjected to flow cytometric analysis.

In vitro tumor spheroid formation assay. Cells at 5x103/well were inoculated in a 24-well culture plate and cultured in serum-free DMEM/F12 medium (Invitrogen, Carlsbad, CA, USA) with (experimental group) or without (control group) $10 \mathrm{ng} / \mathrm{ml}$ basic fibroblast growth factor (bFGF) and $20 \mathrm{ng} / \mathrm{ml}$ epidermal growth factor (EGF) (both from Gibco, Grand Island, NY, USA). The medium was changed every three days. The culture was terminated after two weeks and tumor spheroids exceeding $75 \mu \mathrm{m}$ were counted.

In vivo tumor formation assay. Cells were sorted into four groups: i) $\mathrm{CD}_{133^{+}}$, ii) $\mathrm{CD} 133^{-}$, iii) $\mathrm{CD}_{4} 4^{+}$and iv) $\mathrm{CD} 44^{-}$. For each group of four female nude (NOD/SCID) mice, $10^{3}, 10^{4}$, $10^{5}$ and $10^{6}$ cells were injected subcutaneously in the front flanks of the mice. Tumors exceeding $50 \mathrm{~mm}^{3}$ were counted to determine the minimum number of inoculated cells required for tumor formation in vivo. The mice $(100)$ were purchased from Vital River Laboratories (Beijing, China). All animal handling and procedures were approved by the Animal Care and Use Committee of the General Hospital of Guangzhou Military Command of PLA.

Statistical analysis. Data are expressed as the mean \pm standard deviation. SPSS 20.0 software (IBM Corp., Armonk, NY, USA) was used for statistical analysis. The t-test was used to compare data between two groups. Single factor analysis of variance (ANOVA) was used to compare data among groups. $\mathrm{P}<0.05$ was considered to indicate a statistically significant difference.

\section{Results}

Characterization of NSCLC sublines with AR to gefitinib. The sensitivity of PC-9/ZD and PC-9/GR cells to gefitinib was significantly lower compared to $\mathrm{PC}-9$ cells $(\mathrm{P}<0.05)$, while the sensitivity of PC-9/ZD and PC-9/GR to gefitinib was similar $(\mathrm{P}>0.05)$. The inhibitory concentrations at $50 \%\left(\mathrm{IC}_{50}\right)$ of growth in PC-9/ZD, PC-9/GR and PC-9 cells were 7.85 \pm 0.21 , $10.62 \pm 0.19$ and $0.05 \pm 0.005 \mu \mathrm{mol} / 1$, respectively. PC-9/ZD cells carried the T790M mutation in addition to the delE746-A750 in exon 19. T790M was not detected in the PC-9/GR cells. No c-MET amplification was detected in any of the cell lines as determined by FISH assays (data not shown).

Sensitivity of resistant sublines to various chemotherapeutic drugs. Cytotoxicity assays revealed that PC-9/ZD cells had higher sensitivity to paclitaxel and docetaxel compared to PC-9 cells $(\mathrm{P}<0.05$; Table I). PC-9/ZD and PC-9 cells were similar in sensitivity to cisplatin, gemcitabine and pemetrexed ( $\mathrm{P}>0.05$; Table I). PC-9/GR cells were less sensitive to all chemotherapeutic drugs tested, including cisplatin, gemcitabine, pemetrexed, paclitaxel and docetaxel, compared to PC-9 and PC-9/ZD cells ( $\mathrm{P}<0.05$; Table I).

T790M increases sensitivity of PC-9 cells to chemotherapy. A total of four siRNAs targeting T790M (2597, 2600, 2603 and 2608) and one control (scrambled sequence) were examined. We observed that siRNA-2603 minimally inhibited WT EGFR (Fig. 1A), but it had the greatest inhibitory effect on T790M EGFR (Fig. 1B). Western blot analysis demonstrated that siRNA-2603 had the least inhibitory effect on EGFR (Fig. 1C). Consequently 2603 and the empty vector control were transfected into PC-9/ZD cells to assess the effect on downstream EGFR signaling pathways. The transfection of 2603 did not affect the expression of AKT, p-AKT, ERK and p-ERK (P>0.05; Fig. 1D), indicating that $2603 \mathrm{had}$ no effect on the AKT and ERK pathways. The sensitivity of 2603-treated PC-9/ZD cells to gefitinib was significantly higher compared to the control. The $\mathrm{IC}_{50}$ value of gefitinib was $0.016 \mu \mathrm{mol} / 1$ vs. $1.91 \mu \mathrm{mol} / 1$ ( $\mathrm{P}<0.05$, data not shown).

Treatment with 2603 markedly decreased the $\mathrm{IC}_{50}$ values in PC-9/ZD cells from $15.762 \pm 1.673$ to $0.124 \pm 0.231 \mu \mathrm{mol} / 1$ $(\mathrm{P}<0.05)$ for paclitaxel and from $21.110 \pm 2.165$ to $0.800 \pm 0.109 \mathrm{nmol} / 1$ for docetaxel $(\mathrm{P}<0.05)$, indicating that knockdown of T790M EGFR significantly reduced sensitivity to taxanes (data not shown).

PC-9/GR cells display EMT properties. Western blot analysis revealed that E-cadherin was decreased and vimentin and 

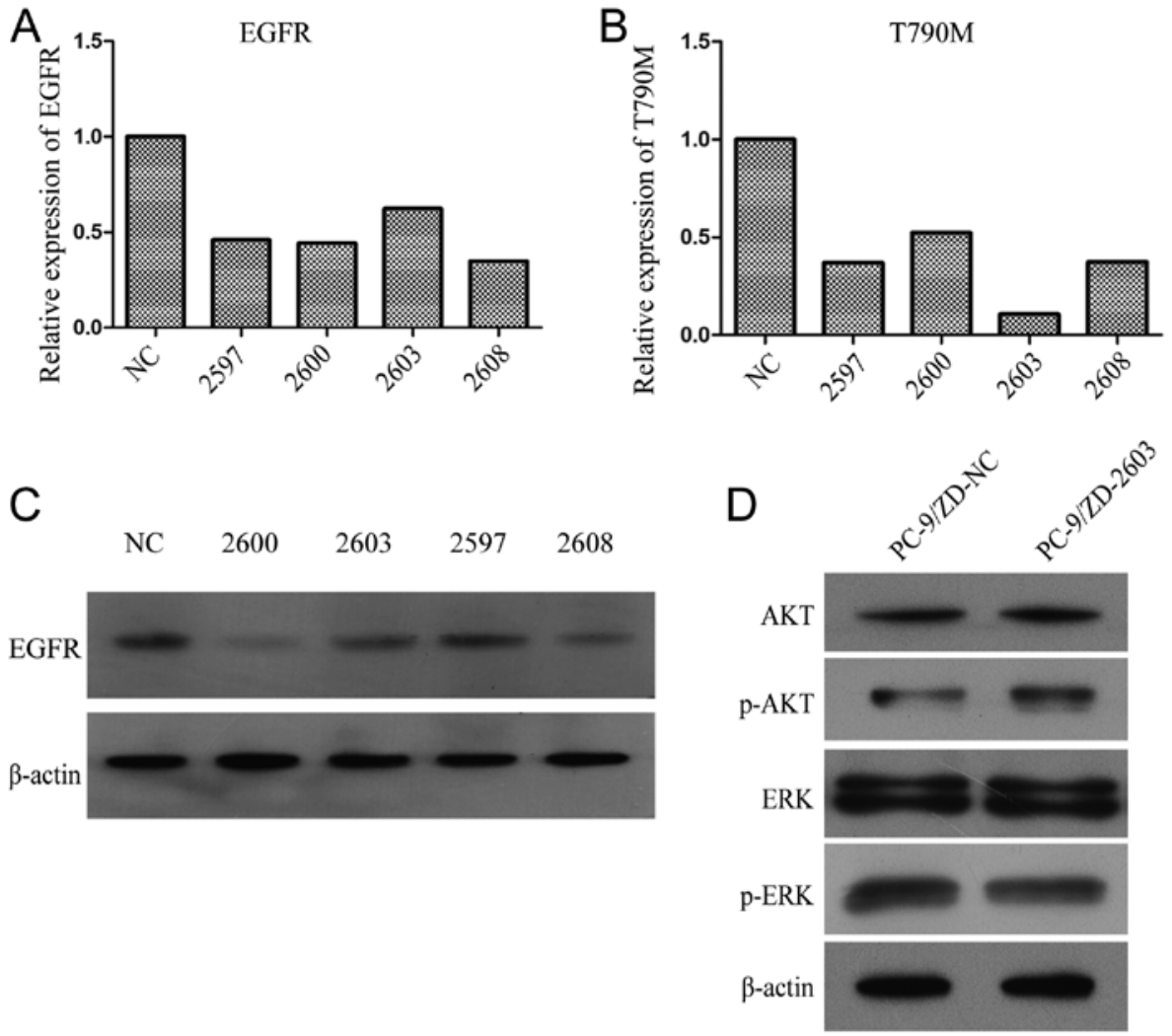

Figure 1. siRNA-mediated knockdown of T790M. Relative expression of (A) EGFR and (B) T790M in PC-9 cells, as determined by real-time PCR after transfection of siRNA $(2608,2597,2603,2600$ and NC) expressing lentiviral vectors. (C) Western blot analysis of total EGFR and $\beta$-actin protein in PC-9 cells after transfection of siRNA as indicated. (D) Western blot analysis of ERK, pERK, AKT, pAKT and $\beta$-actin in PC-9/ZD cells after transfection with siRNA $\mathrm{NC}$ and 2603 expressing lentiviral vectors.

Table II. $\mathrm{IC}_{50}$ values of various chemotherapeutic drugs in PC-9 cells before and after treatment with TGF- $\beta 1$.

\begin{tabular}{lcr}
\hline $\mathrm{IC}_{50}$ & PC-9 & PC-9/TGF- $\beta 1$ \\
\hline Cisplatin $(\mu \mathrm{mol} / \mathrm{l})$ & $3.877 \pm 1.346$ & $15.617 \pm 0.811^{\mathrm{a}}$ \\
Gemcitabine $(\mu \mathrm{mol} / \mathrm{l})$ & $0.145 \pm 0.724$ & $1.667 \pm 0.101^{\mathrm{a}}$ \\
Pemetrexed $(\mu \mathrm{mol} / \mathrm{l})$ & $30.517 \pm 4.69$ & $246.197 \pm 4.883^{\mathrm{a}}$ \\
Paclitaxel $(\mathrm{nmol} / \mathrm{l})$ & $1.532 \pm 0.777$ & $10.377 \pm 0.891^{\mathrm{a}}$ \\
Docetaxel $(\mathrm{nmol} / \mathrm{l})$ & $5.226 \pm 0.648$ & $36.110 \pm 3.360^{\mathrm{a}}$
\end{tabular}

aindicates statistically significant difference from the $\mathrm{IC}_{50}$ values in PC-9 cells $(\mathrm{P}<0.05)$.

$\mathrm{N}$-cadherin were increased in PC-9/GR cells, but not in PC-9/ZD cells, indicating that PC-9/GR cells but not PC-9/ZD cells acquired the EMT phenotype $(\mathrm{P}<0.05$, Fig. $2 \mathrm{~A})$. In addition, PC-9/GR cells exhibited mesenchymal morphology, with cells being long, polarized and sparsely connected (Fig. 2B). Furthermore, PC-9/GR cells undergoing EMT exhibited higher migration and invasion abilities than PC-9 cells without EMT $(\mathrm{P}<0.05)$, whereas no significant difference of the migration and invasion abilities was observed between PC-9/ZD and PC-9 cells ( $\mathrm{P}>0.05$; Fig. 2C-F).

EMT decreases sensitivity to chemotherapy in AR-cell lines. Application of exogenous TGF- $\beta 1(10 \mathrm{ng} / \mathrm{ml})$ to parental PC-9
Table III. $\mathrm{IC}_{50}$ values of chemotherapeutic agents in PC-9/GR cells after the overexpression of E-cadherin by $\mathrm{CDH} 1$ transfection.

\begin{tabular}{lrr}
\hline $\mathrm{IC}_{50}$ & PC-9/GR-CDH1 & PC-9/GR-control \\
\hline Cisplatin $(\mu \mathrm{mol} / \mathrm{l})$ & $3.987 \pm 0.818^{\mathrm{a}}$ & $17.28 \pm 0.445$ \\
Gemcitabine $(\mu \mathrm{mol} / \mathrm{l})$ & $0.267 \pm 0.098^{\mathrm{a}}$ & $3.546 \pm 0.120$ \\
Pemetrexed $(\mu \mathrm{mol} / \mathrm{l})$ & $35.497 \pm 2.075^{\mathrm{a}}$ & $348.856 \pm 1.875$ \\
Paclitaxel $(\mathrm{nmol} / \mathrm{l})$ & $2.484 \pm 0.908^{\mathrm{a}}$ & $19.429 \pm 0.937$ \\
Docetaxol $(\mathrm{nmol} / \mathrm{l})$ & $7.838 \pm 2.885^{\mathrm{a}}$ & $73.676 \pm 2.840$ \\
\hline
\end{tabular}

aindicates statistically significant difference from the $\mathrm{IC}_{50}$ value in PC-9/GR control cells $(\mathrm{P}<0.05)$.

cells successfully induced EMT after $72 \mathrm{~h}$ and decreased the sensitivity to gefitinib. The sensitivity of PC-9 cells treated with exogenous TGF- $\beta 1(10 \mathrm{ng} / \mathrm{ml})$ to different chemotherapeutic agents was assessed $72 \mathrm{~h}$ after treatment. TGF- $\beta 1$ significantly inhibited the chemotherapeutic effect of gemcitabine, paclitaxel, docetaxel and cisplatin, as evidenced by decreased $\mathrm{IC}_{50}$ values $(\mathrm{P}<0.05$; Table II).

PC-9/GR cells that overexpressed E-cadherin following $\mathrm{CDH} 1$ transfection had significantly increased sensitivity to gemcitabine, paclitaxel, pemetrexed, docetaxel and cisplatin, as evidenced by the increased IC $_{50}$ values $(\mathrm{P}<0.05$, Table III). 
A
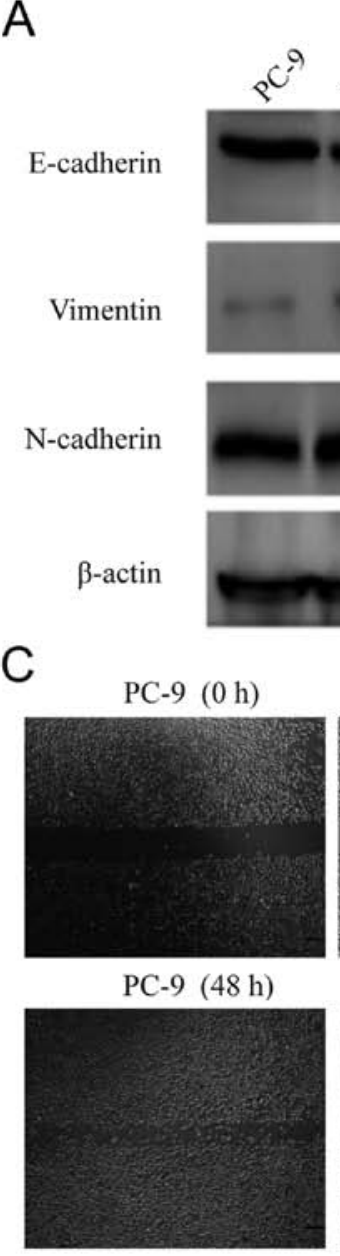

E

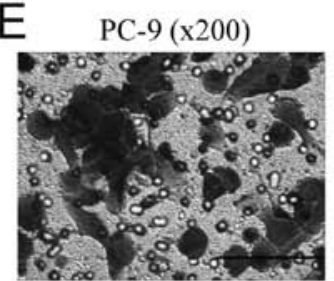

B
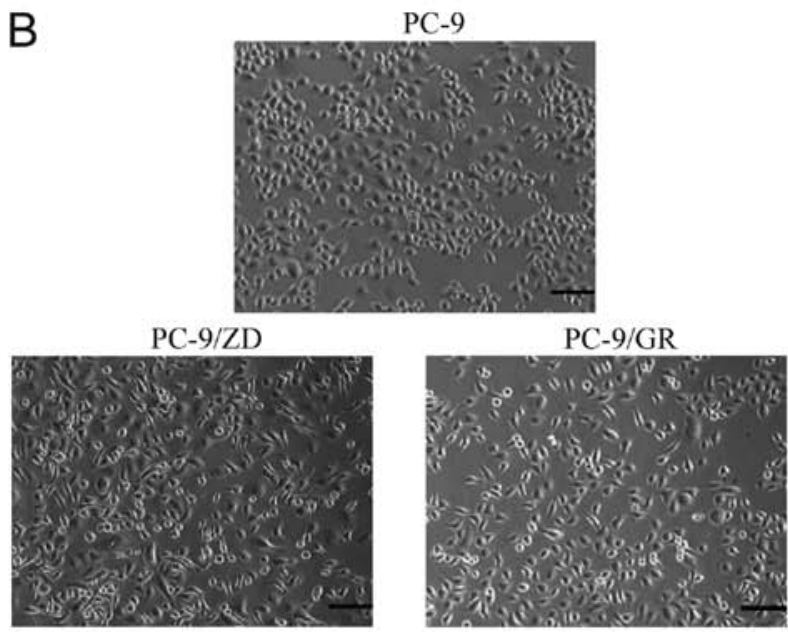

D

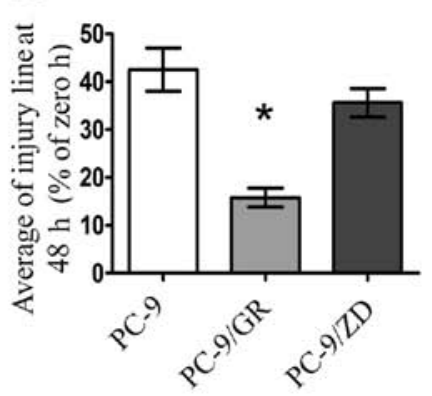

F

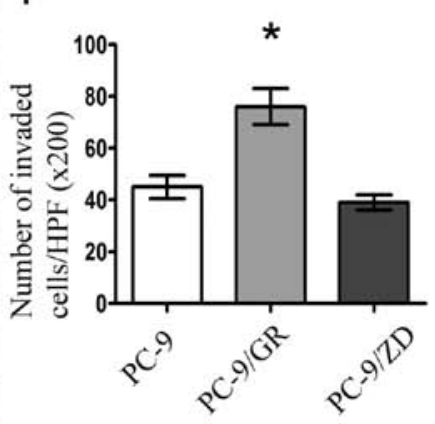

Figure 2. PC-9/GR cells display EMT. (A) Western blot analysis revealed that E-cadherin decreased and vimentin and N-cadherin increased in PC-9/GR cells, but not in PC-9/ZD cells, compared to PC-9 cells. (B) Representative fields of PC-9, PC-9/ZD and PC-9/GR cells under phase-contrast microscopy. (C) Representative images of scratch assays of PC-9, PC-9/GR and PC-9/ZD cells at 0 and 48 h post-scratch wound. (D) Quantitative results of scratch assay displaying average injury in PC-9, PC-9/ZD and PC-9/GR cells at $48 \mathrm{~h}$ post-scratch wound. (E) Representative fields of invasion assays in PC-9, PC-9/ZD and PC-9/GR cells under phase-contrast microscopy. Cells were stained with crystal violet. (F) Number of invaded PC-9, PC-9/ZD and PC-9/GR cells. * $<0.05$ vs. PC-9 groups (n=3). Scale bar, $200 \mu \mathrm{m}$.

EMT is associated with increased CSCs in NSCLC sublines. Previous studies have used CD44 and CD133 as markers for CSCs in NSCLC cells (11-13). Thus, we determined the expression of CD44 and CD133 in PC-9 cell lines by flow cytometry. The percentage of $\mathrm{CD}_{133^{+}}$cells in the PC-9 cell line was $0.2 \%$ (Fig. 3A) and the percentage of $\mathrm{CD} 44^{+}$cells was $94.1 \%$ (Fig. 3B). To further confirm whether CD44 and CD133 can be used as CSC surface markers in PC-9 derived cells, we first separated PC-9/GR cells into CD133 ${ }^{+}, \mathrm{CD} 133^{-}$, CD $44^{+}$and CD44- cell groups using MACS and assessed their tumor formation activity both in vitro and in vivo. The number of spheroids formed in the in vitro assays was significantly higher in $\mathrm{CD} 133^{+}$cells $(452 \pm 10.60)$ compared to $\mathrm{CD} 133^{-}$cells (4.67 \pm 0.88$)(\mathrm{P}<0.05$, Fig. $3 \mathrm{C})$. In vivo, tumorigenicity in

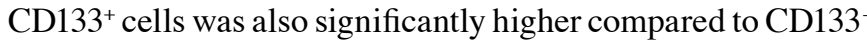
cells (Fig. 3D). The $\mathrm{CD}_{133^{+}}$cells required only $10^{3}$ cells to form tumors, while the CD133- cells did not form tumors even when injected with $10^{6}$ cells (Fig. 3D). These results indicated that $\mathrm{CD}_{133^{+}}$cells had a strong self-renewal and differentiation ability. Thus, $\mathrm{CD} 133^{+}$can be used as a CSC marker in PC-9-derived cells. However, there was no significant difference between $\mathrm{CD}_{4} 4^{+}$and $\mathrm{CD} 44^{-}$cells in tumor formation capability both in vitro and in vivo ( $\mathrm{P}>0.05$, Fig. $3 \mathrm{E}$ and $\mathrm{F})$.

PC-9/GR cells expressed a much higher percentage of CD133 ${ }^{+}$compared to PC-9 and PC-9/ZD cells ( $\mathrm{P}<0.05$, Fig. 4A). The percentage of $\mathrm{CD}_{133^{+}}$cells was $0.20 \pm 0.02 \%$ in PC-9, $0.50 \pm 0.04 \%$ in $\mathrm{PC}-9 / \mathrm{ZD}$ and $3.00 \pm 0.22 \%$ in $\mathrm{PC}-9 / \mathrm{GR}$ cells. Side population assays revealed that the number of cells in 


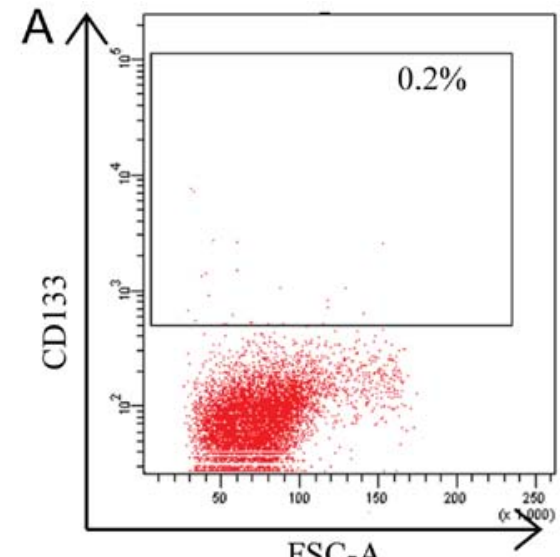

FSC-A

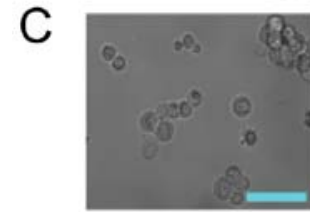

CD133-

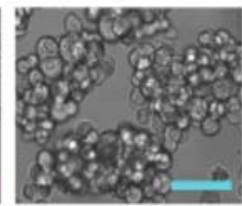

$\mathrm{CD} 133^{+}$

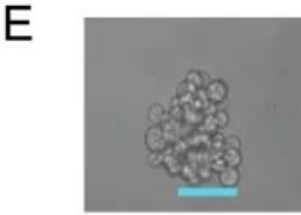

CD $44^{+}$

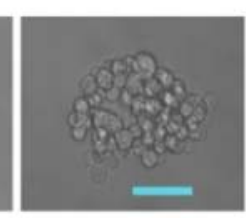

CD44-

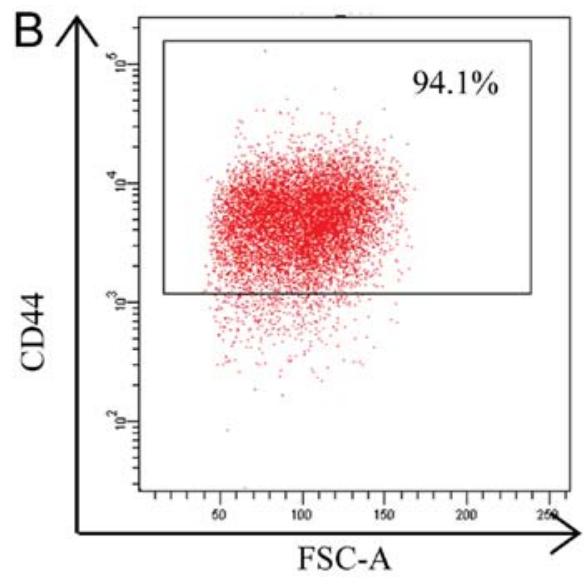

D

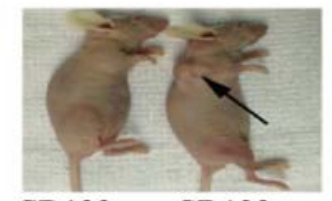

CD133- CD133+ $^{+}$

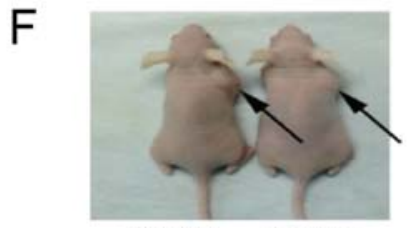

$\mathrm{CD}_{4} 4^{+} \mathrm{CD} 44^{-}$

Figure 3. CD133+ PC-9 cells displayed CSC properties. Flow cytometric analysis of PC-9 cells stained with (A) CD133 and (B) CD44. The percentages of $\mathrm{CD}_{133^{+}}$and $\mathrm{CD}_{4} 4^{+}$cells are displayed. (C) Spheroid formation assay revealed that CD133 ${ }^{+} \mathrm{PC}-9$ cells had a higher ability to form spheroids compared to CD133. (D) In vivo tumor formation assays demonstrated that CD133 ${ }^{+}$PC-9 cells had a higher ability to form tumor compared to CD133 ${ }^{-}$in nude (NOD/SCID) mice. (E) Spheroid formation assay revealed that CD44 ${ }^{+}$and CD4- PC-9 cells had a similar ability to form spheroids. (F) In vivo tumor formation assays revealed that $\mathrm{CD}_{4} 4^{+}$and $\mathrm{CD} 44^{-}$PC-9 cells had a similar ability to form tumors in nude mice.

the PC-9/GR cell line was increased $(1.50 \pm 0.24 \%)$ compared to the PC-9 and PC-9/ZD cell lines $(\mathrm{P}<0.05$, Fig. 4B). Furthermore, the side-population cells were essentially eliminated by verapamil. The tumor-forming ability of PC-9/GR cells was significantly higher compared to PC-9 and PC-9/ZD cells $(\mathrm{P}<0.05$, Fig. 4C).

These results indicated that PC-9/GR cells with EMT displayed more prominent stem cell characteristics. To further demonstrate the effect of EMT on CSCs, we repeated the assays by overexpressing CDH1 in the PC-9/GR cells to reverse EMT, as well as by treating PC-9 cells with TGF- $\beta 1$ to induce EMT. The percentage of $\mathrm{CD}_{133^{+}}$and side population cells significantly decreased when PC-9/GR cells were transfected with CDH1 ( $\mathrm{P}<0.05$, Fig. 5A and B). Furthermore, the number of both $\mathrm{CD}_{133}{ }^{+}$and side population cells increased in PC-9 cells in response to TGF- $\beta 1$ (Fig. $5 \mathrm{~A}$ and $\mathrm{B}$ ).

TGF- $\beta 1$ induces EMT of NSCLC cells. To demonstrate the EMT of the NSCLC cells, PC-9 cells were treated with a potent EMT inducer TGF- $\beta 1$ at different concentrations ranging from 0.1 to $100 \mathrm{ng} / \mathrm{ml}$. As displayed in Fig. 6, vehicletreated PC-9 cells maintained a flattened shape which is a prominent feature of the epithelial phenotype. In contrast, TGF- $\beta 1$-treated cells exhibited a spindle-shaped morphology and $10 \mathrm{ng} / \mathrm{ml}$ of TGF- $\beta 1$ induced the most pronounced mesenchymal phenotype while having no effect on cell viability.
These results indicated that TGF- $\beta 1$ induces EMT in a dosedependent manner.

\section{Discussion}

In the present study, we investigated the association between sensitivity of gefitinib-resistant NSCLC cell lines to chemotherapeutic drugs and the underlying molecular mechanisms of resistance to gefitinib, using two distinct PC-9 derived gefitinib-resistant sublines, PC-9/ZD and PC-9/GR. We confirmed that increased sensitivity of the PC-9/ZD cell line to taxanes was associated with the T790M mutation and decreased sensitivity of the PC-9/GR cell line to various chemotherapeutics was associated with EMT. Furthermore, we revealed that the promotion of CSC properties may be one of the mechanisms for the increased resistance to chemotherapeutics in the EMT phenotype in NSCLC cells.

T790M accounts for $\sim 50 \%$ of AR cases in patients with NSCLC. After prolonged exposure to EGFR-TKIs, the T790M mutant allele becomes enriched, resulting in AR to EGFRTKIs (1). Rosell et al (5) reported that among AR NSCLC patients, T790M-positive patients had better outcomes (longer PFS and OS) than T790M-negative patients when treated with chemotherapy, indicating that tumors with AR due to the T790M mutation are more sensitive to chemotherapy. Kuo et al (4) observed that patients with AR to EGFR-TKIs 

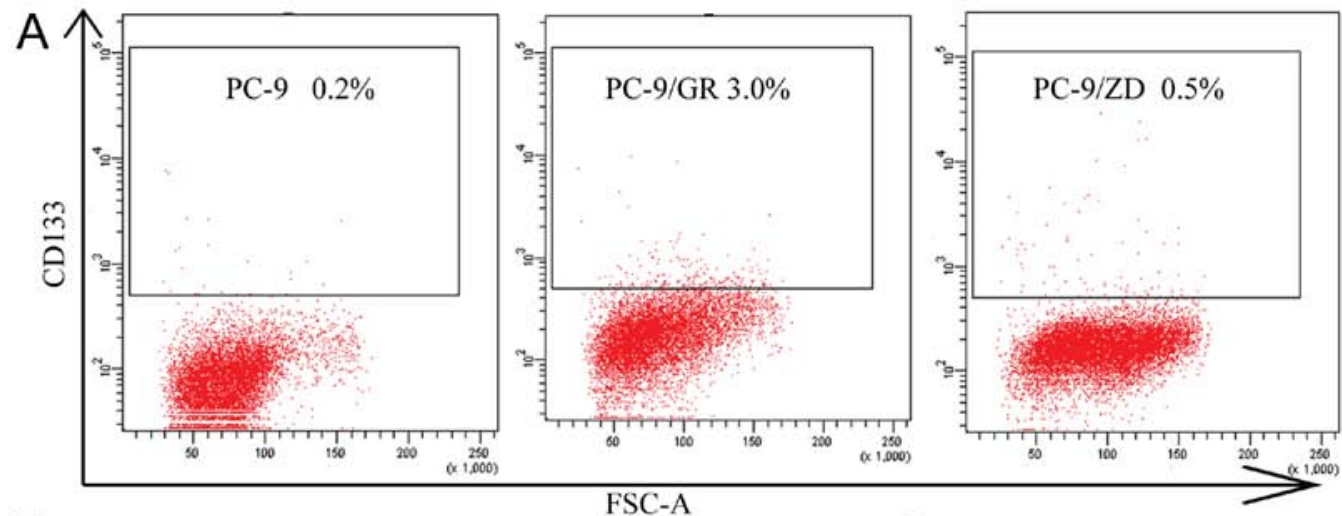

B

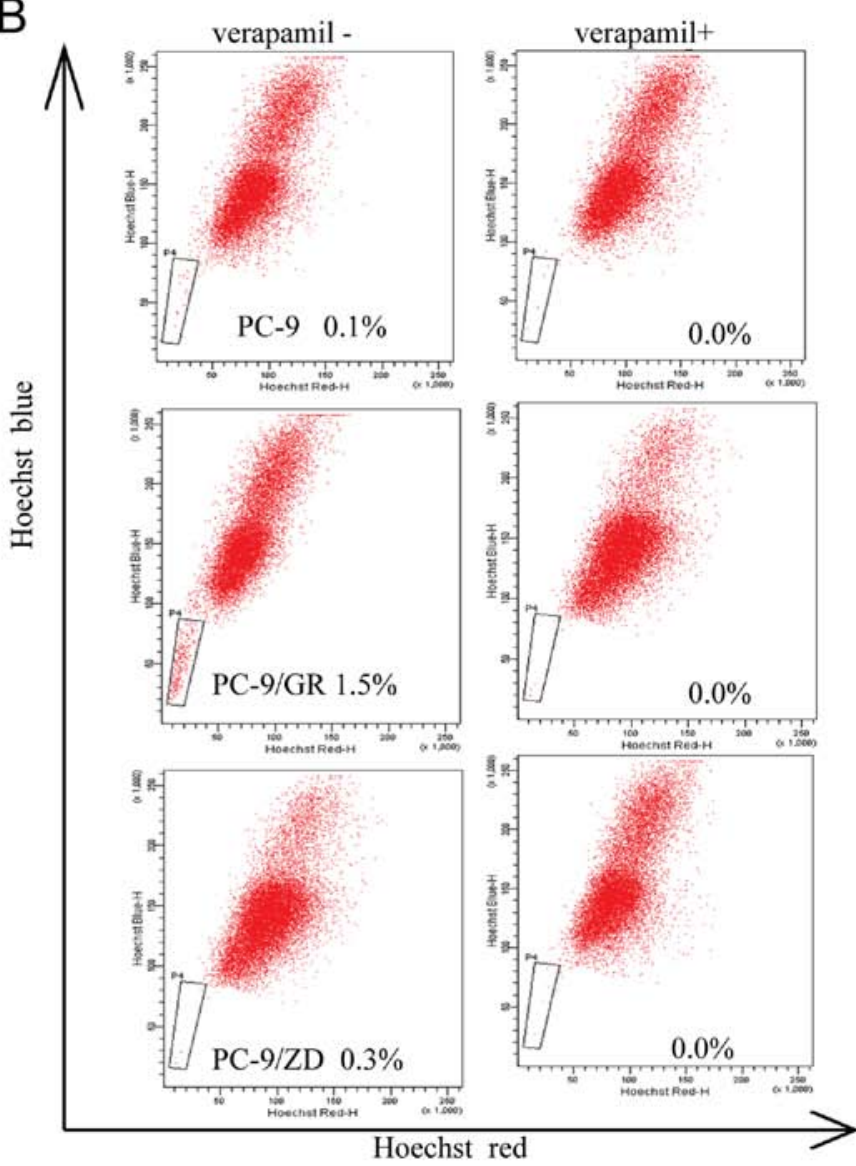

C

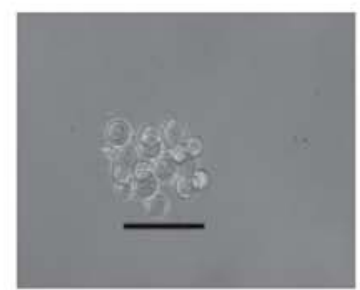

PC-9 $\mathrm{n}=17$

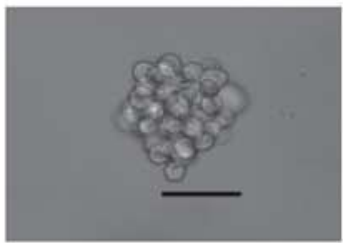

PC-9/GR $n=71$

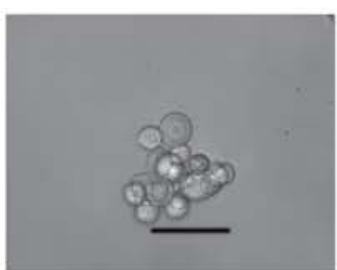

PC-9/ZD n=18

Figure 4. Flow cytometric analysis of putative CSC marker (CD133 and CD44) expression and side-population in PC-9, PC-9/ZD and PC-9/GR cells. (A) Flow cytometry indicated that PC-9/GR cells expressed a higher percentage of CD133 cells compared to PC-9 and PC-9/ZD cells. (B) Side population analysis by flow cytometry revealed that the percentage of side-population in PC-9/GR cells was higher compared to PC-9 and PC-9/ZD cells. The side-population cells were nearly eliminated by verapamil treatment. (C) Representative images of in vitro spheroid formation assays in PC-9, PC-9/ZD and PC-9/GR cells, as indicated. The number of spheroids of each cell line is displayed.

achieved better response rates and longer PFS and OS in response to taxane chemotherapy. Although the underlying mechanisms remained unknown in their study, the study indicated that the improved outcomes following taxane chemotherapy were due to higher sensitivity of T790M positive tumors.

In the present study, we first revealed the relationship between the T790M mutation and the sensitivity to chemotherapy in vitro. We identified that PC-9/ZD cells with the T790M mutation were resistant to gefitinib and had a higher sensitivity to taxanes (paclitaxel and docetaxel). Our findings were different from the ones of the study by Cheng et al (12), which revealed no significant change in sensitivity to paclitaxel before and after AR to gefitinib. The discrepancy is probably due to differences in the ratio of the T790M allele to the WT allele. Our resistant PC-9/ZD cells were pure and were derived from a single T790M mutant cell, while only $30 \%$ of the cells used by Cheng et al were T790M positive. To further confirm the correlation between the T790M mutation and sensitivity to chemotherapy, we used siRNA to specifically knock down T790M (8) and found that sensitivity of the PC-9/ZD cells to paclitaxel and docetaxel decreased, indicating that the T790M mutation is a useful marker for taxane chemotherapy sensitivity. 

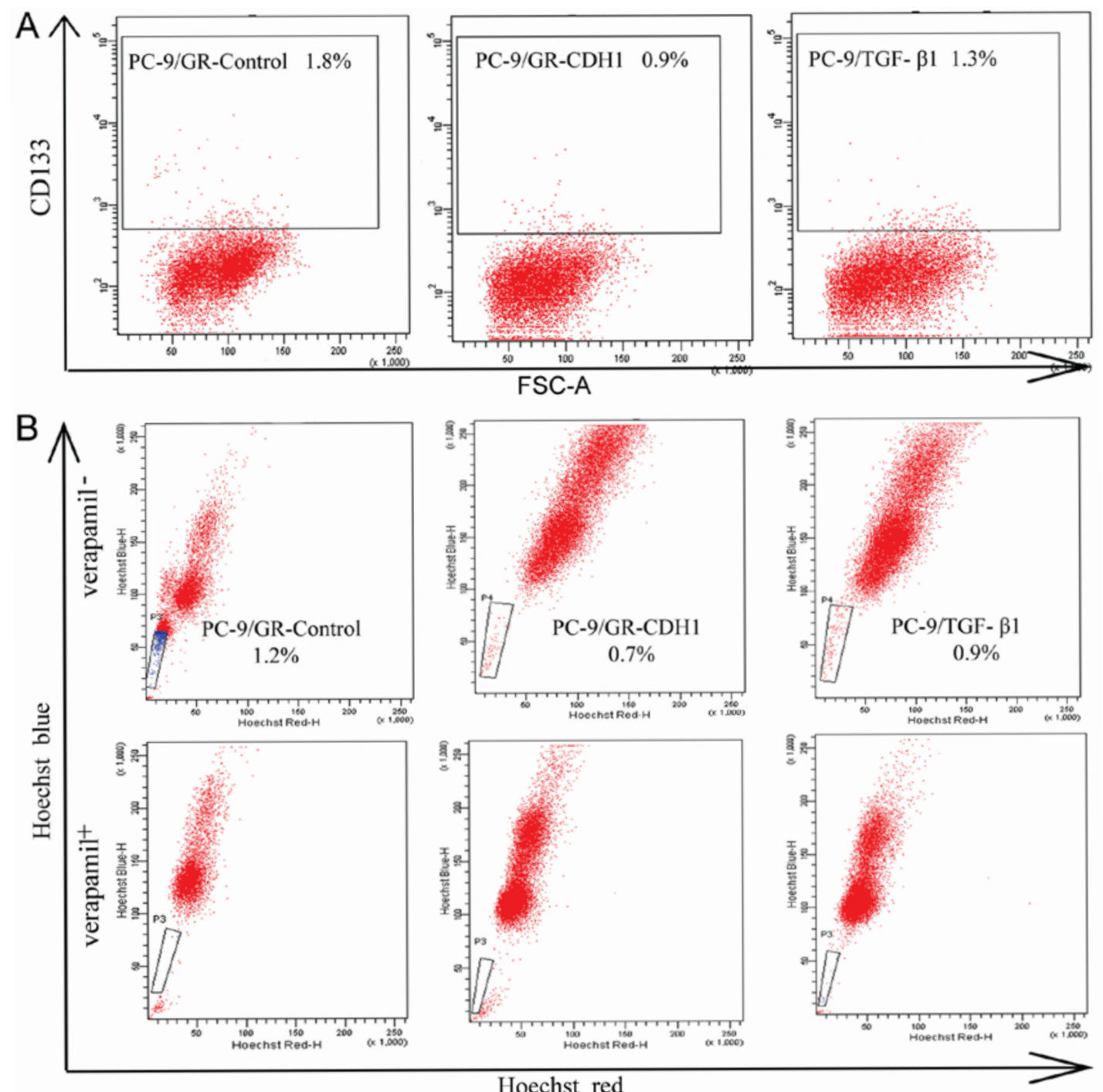

Figure 5. Flow cytometric analysis of the CSC properties of PC-9 cells treated with TGF- $\beta 1$ and PC-9/GR cells transfected with CDH1. (A) Flow cytometry revealed that the expression of $\mathrm{CD}_{133^{+}}$in PC-9/GR cells decreased when $\mathrm{CDH} 1$ was overexpressed and the expression of CD133 ${ }^{+}$in PC-9 cells increased in response to TGF- $\beta 1$ after $72 \mathrm{~h}$. (B) Flow cytometry side population assays revealed that the number of side population in PC-9/GR cells decreased when CDH1 was overexpressed. The side population in PC-9 increased in response to TGF- $\beta 1$ after $72 \mathrm{~h}$.

Numerous previous studies have revealed that EMT contributes to AR to EGFR-TKIs in NSCLC (2,14-16). It has also been reported that NSCLC patients with EMT-positive tumors are resistant to chemotherapy and such patients have poor prognoses $(2,6,13)$. In the present study, we revealed that PC-9/GR cells with EMT were significantly less sensitive to chemotherapeutic agents (gemcitabine, paclitaxel, pemetrexed, docetaxel and cisplatin) compared to parental PC-9 cells. Furthermore, we revealed that TGF- $\beta 1$-induced EMT in PC-9 cells conferred resistance to chemotherapy. This is consistent with the study by Shintani et al (6) who found that the sensitivity of cells to the chemotherapeutic drugs cisplatin and paclitaxel decreased after TGF- $\beta 1$-induced EMT in NSCLC cells, indicating that EMT plays an important role in tumor cell chemotherapeutic resistance (6). Furthermore, we demonstrated that when EMT in PC-9/GR cells was reversed by the overexpression of $\mathrm{CDH} 1$ the cells became less resistant to chemotherapeutic agents. These results further confirmed that EMT in NSCLC cells is directly associated with chemotherapeutic resistance. Previous studies have also demonstrated that EMT in other types of tumor cells, such as pancreatic cancer (17), colon carcinoma (18) and ovarian cancer (19), lead to chemotherapeutic resistance.

Previous studies have revealed that EMT promotes the formation of cells with the CSC phenotype (20-22). The expression profiles of stem cell-related genes, including Oct4, Wnt, Notch, Hedgehog and Nanog $(23,24)$, are altered in the process of EMT. This alteration is associated with the proliferation of CSCs, leading to increased resistance to chemotherapy (25). The present study revealed that PC-9/GR cells with EMT had an increase in the number of $\mathrm{CD}_{133^{+}}$and side population cells. These cells had tumor stem cell characteristics, indicating that the increased resistance to chemotherapeutic drugs in EMT-positive cells may be related to the increase in CSCs. Shien et al (20) also revealed that in cells with AR to EGFRTKIs, CSC characteristics of the sub-groups led to resistance to subsequent chemotherapy. We further confirmed the correlation between EMT and CSCs. We revealed that the number of CSCs was increased in the PC-9 cells in response to TGF- $\beta 1$ induced EMT. This finding indicated that the production 


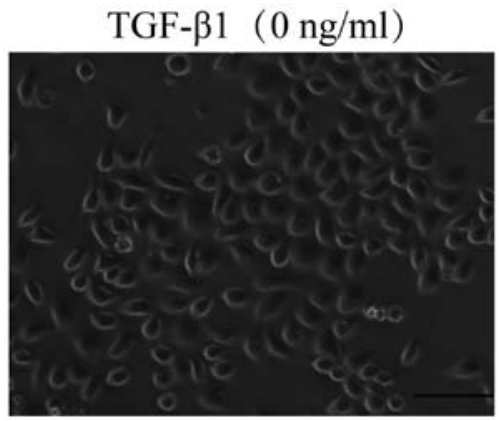

TGF- $\beta 1(1 \mathrm{ng} / \mathrm{ml})$

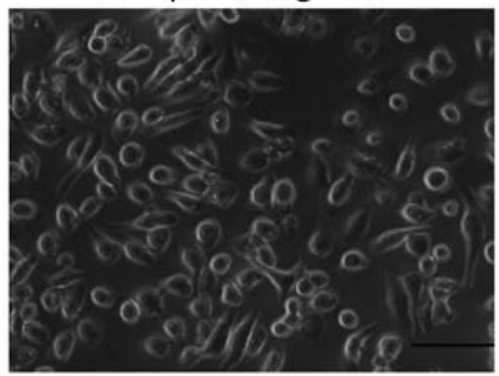

TGF- $\beta 1(100 \mathrm{ng} / \mathrm{ml})$

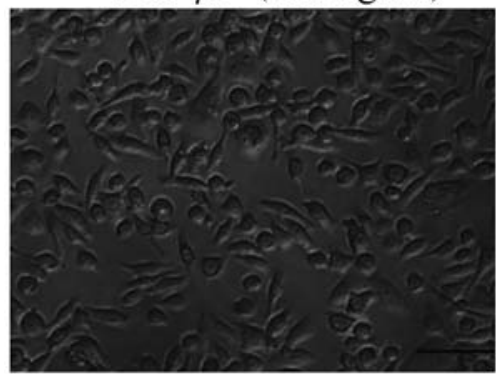

TGF- $\beta 1(0.1 \mathrm{ng} / \mathrm{ml})$

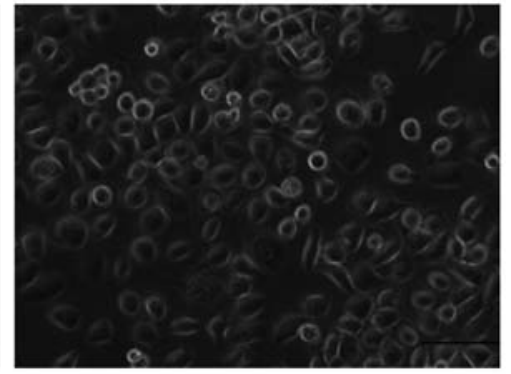

TGF- $\beta 1 \quad(10 \mathrm{ng} / \mathrm{ml})$
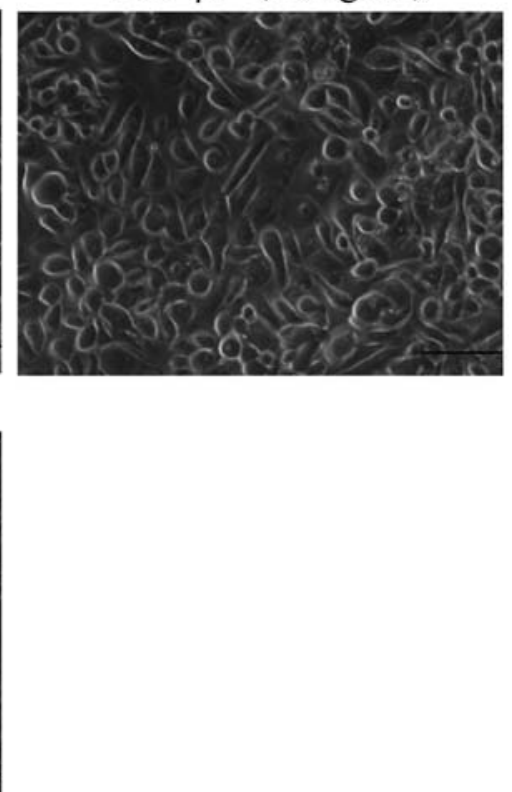

Figure 6. TGF- $\beta 1$ induces EMT in NSCLC cells. PC-9 cells were treated with a vehicle or TGF- $\beta 1$ at different concentrations as indicated for $72 \mathrm{~h}$ and microphotographs were captured under a light microscope. Scale bar, $200 \mu \mathrm{m}$.

of CSCs may be one of the contributing factors to the resistance of EMT-positive cells to chemotherapy. However, it is worth noting that only $3.0 \%$ of the PC-9/GR cells were CSCs in the present study. Thus, further investigation is necessary to determine if CSCs are a primary factor in chemotherapy resistance.

NSCLC patients with EGFR-activating mutations initially respond very well to EGFR-TKIs, such as gefitinib and erlotinib, when administered as first-line treatments (2). However, all patients eventually develop resistance to EGFR-TKIs $(1,2)$. Thus, it is critical to develop treatments that can overcome EGFR-TKI resistance by targeting the underlying mechanisms responsible for the resistance (26-29). The majority of NSCLC patients develop resistance that is mediated by the T790M mutation. Thus, much effort has been made to develop a third generation of EGFR-TKIs that target both the activating mutations, such as deletion in exon 19, and T790M. Third generation inhibitors include AZD9291, HM61713 and CO-1686. These inhibitors have shown early promise in clinical trials, with objective response rates ranging from 58-66\% (2). However, there is no doubt that NSCLC patients will quickly develop resistance, since resistance to $\mathrm{CO}-1686$ has already been demonstrated by an EMT mechanism (2). To target the mechanisms associated with EMT, histone deacetylase (HDAC) inhibitors and MAPK/ERK kinase (MEK) inhibitors are being developed to delay the onset or reverse EMT (2). Such efforts have only achieved limited success, therefore subsequent chemotherapy remains an important choice of treatment after AR to EGFR-TKIs. In the present study, we confirmed that NSCLC cells with AR mediated by T790M had higher sensitivity to taxanes and those mediated by EMT were resistant to various chemotherapeutic drugs including taxanes and nontaxanes. These results provide a rationale for the selection of appropriate chemotherapeutic regimens to maximally benefit patients with intrinsic or acquired EGFR-TKI resistance.

\section{Acknowledgements}

The present study was supported by grants from the National Natural Science Foundation of China (nos. 81472172 and 81172225), and The Science and Technology Planning Project of Guangdong Province (no. 2014A020212254).

\section{Competing interests}

The authors declare that they have no competing interests.

\section{References}

1. Stewart EL, Tan SZ, Liu G and Tsao MS: Known and putative mechanisms of resistance to EGFR targeted therapies in NSCLC patients with EGFR mutations - a review. Transl Lung Cancer Res 4: 67-81, 2015. 
2. Jakobsen KR, Demuth C, Sorensen BS and Nielsen AL: The role of epithelial to mesenchymal transition in resistance to epidermal growth factor receptor tyrosine kinase inhibitors in non-small cell lung cancer. Transl Lung Cancer Res 5: 172-182, 2016.

3. Suda K, Tomizawa K, Fujii M, Murakami H, Osada H, Maehara Y, Yatabe Y, Sekido Y and Mitsudomi T: Epithelial to mesenchymal transition in an epidermal growth factor receptormutant lung cancer cell line with acquired resistance to erlotinib. J Thorac Oncol 6: 1152-1161, 2011.

4. Kuo CH, Lin SM, Lee KY, Chung FT, Hsieh MH, Fang YF, Yu CT and Kuo HP: Subsequent chemotherapy improves survival outcome in advanced non-small-cell lung cancer with acquired tyrosine kinase inhibitor resistance. Clin Lung Cancer 11: 51-56, 2010.

5. Rosell R, Molina-Vila MA, Taron M, Bertran-Alamillo J, Mayo C, Vergnenegre A, De Marinis F, Massuti B, De Castro J, Gervais R, et al: EGFR compound mutants and survival on erlotinib in non-small cell lung cancer (NSCLC) patients (p) in the EURTAC study. J Clin Oncol 30 (15 Suppl): S7522, 2012

6. Shintani Y, Okimura A, Sato K, Nakagiri T, Kadota Y, Inoue M, Sawabata N, Minami M, Ikeda N, Kawahara K, et al: Epithelial to mesenchymal transition is a determinant of sensitivity to chemoradiotherapy in non-small cell lung cancer. Ann Thorac Surg 92: 1794-1804, 2011.

7. Zhou J, Wang J, Zeng Y, Zhang X, Hu Q, Zheng J, Chen B, Xie B and Zhang WM: Implication of epithelial-mesenchymal transition in IGF1R-induced resistance to EGFR-TKIs in advanced non-small cell lung cancer. Oncotarget 6: 44332-44345, 2015.

8. Chen G, Kronenberger P, Teugels E, Umelo IA and De Grève J: Effect of siRNAs targeting the EGFR T790M mutation in a non-small cell lung cancer cell line resistant to EGFR tyrosine kinase inhibitors and combination with various agents. Biochem Biophys Res Commun 431: 623-629, 2013.

9. Chen G, Kronenberger P, Teugels E, Umelo IA and De Grève J: Targeting the epidermal growth factor receptor in non-small cell lung cancer cells: The effect of combining RNA interference with tyrosine kinase inhibitors or cetuximab. BMC Med 10: 28, 2012.

10. Chen G, Kronenberger P, Umelo IA, Teugels E and De Grève J: Quantification of epidermal growth factor receptor T790M mutant transcripts in lung cancer cells by real-time reverse transcriptase-quantitative polymerase chain reaction. Anal Biochem 398: 266-268, 2010.

11. Ogino A, Kitao H, Hirano S, Uchida A, Ishiai M, Kozuki T, Takigawa N, Takata M, Kiura K and Tanimoto M: Emergence of epidermal growth factor receptor T790M mutation during chronic exposure to gefitinib in a non small cell lung cancer cell line. Cancer Res 67: 7807-7814, 2007.

12. Cheng H, An SJ, Dong S, Zhang YF, Zhang XC, Chen ZH, Jian-Su and Wu YL: Molecular mechanism of the scheduledependent synergistic interaction in EGFR-mutant non-small cell lung cancer cell lines treated with paclitaxel and gefitinib. J Hematol Oncol 4: 5, 2011.

13. Rho JK, Choi YJ, Lee JK, Ryoo BY, Na II, Yang SH, Kim CH and Lee JC: Epithelial to mesenchymal transition derived from repeated exposure to gefitinib determines the sensitivity to EGFR inhibitors in A549, a non-small cell lung cancer cell line. Lung Cancer 63: 219-226, 2009.

14. Mittal V: Epithelial mesenchymal transition in aggressive lung cancers. Adv Exp Med Biol 890: 37-56, 2016.

15. Yin H, Wang Y, Chen W, Zhong S, Liu Z and Zhao J: Drugresistant CXCR4-positive cells have the molecular characteristics of EMT in NSCLC. Gene 594: 23-29, 2016.
16. Rastogi I, Rajanna S, Webb A, Chhabra G, Foster B, Webb B and Puri N: Mechanism of c-Met and EGFR tyrosine kinase inhibitor resistance through epithelial mesenchymal transition in non-small cell lung cancer. Biochem Biophys Res Commun 477: 937-944, 2016.

17. Wang Z, Li Y, Kong D, Banerjee S, Ahmad A, Azmi AS, Ali S, Abbruzzese JL, Gallick GE and Sarkar FH: Acquisition of epithelial-mesenchymal transition phenotype of gemcitabineresistant pancreatic cancer cells is linked with activation of the notch signaling pathway. Cancer Res 69: 2400-2407, 2009.

18. Yang AD, Fan F, Camp ER, van Buren G, Liu W, Somcio R, Gray MJ, Cheng H, Hoff PM and Ellis LM: Chronic oxaliplatin resistance induces epithelial-to-mesenchymal transition in colorectal cancer cell lines. Clin Cancer Res 12: 4147-4153, 2006.

19. Kajiyama H, Shibata K, Terauchi M, Yamashita M, Ino K, Nawa A and Kikkawa F: Chemoresistance to paclitaxel induces epithelialmesenchymal transition and enhances metastatic potential for epithelial ovarian carcinoma cells. Int J Oncol 31: 277-283, 2007.

20. Shien K, Toyooka S, Yamamoto H, Soh J, Jida M, Thu KL, Hashida S, Maki Y, Ichihara E, Asano H, et al: Acquired resistance to EGFR inhibitors is associated with a manifestation of stem cell-like properties in cancer cells. Cancer Res 73: 30513061, 2013.

21. Polyak K and Weinberg RA: Transitions between epithelial and mesenchymal states: Acquisition of malignant and stem cell traits. Nat Rev Cancer 9: 265-273, 2009.

22. Floor S, van Staveren WC, Larsimont D, Dumont JE and Maenhaut C: Cancer cells in epithelial-to-mesenchymal transition and tumor-propagating-cancer stem cells: Distinct, overlapping or same populations. Oncogene 30: 4609-4621, 2011.

23. Chiou SH, Wang ML, Chou YT, Chen CJ, Hong CF, Hsieh WJ, Chang HT, Chen YS, Lin TW, Hsu HS and Wu CW: Coexpression of Oct4 and Nanog enhances malignancy in lung adenocarcinoma by inducing cancer stem cell-like properties and epithelial-mesenchymal transdifferentiation. Cancer Res 70: 10433-10444, 2010.

24. Pirozzi G, Tirino V, Camerlingo R, Franco R, La Rocca A, Liguori E, Martucci N, Paino F, Normanno N and Rocco G: Epithelial to mesenchymal transition by TGF $\beta$-1 induction increases stemness characteristics in primary non small cell lung cancer cell line. PLoS One 6: e21548, 2011.

25. Hu J, Qiu M, Jiang F, Zhang S, Yang X, Wang J, Xu L and Yin R: MiR-145 regulates cancer stem-like properties and epithelial-tomesenchymal transition in lung adenocarcinoma-initiating cells. Tumour Biol 35: 8953-8961, 2014.

26. Kuwano M, Sonoda K, Murakami Y, Watari K and Ono M: Overcoming drug resistance to receptor tyrosine kinase inhibitors: Learning from lung cancer. Pharmacol Ther 161: 97-110, 2016.

27. Pirazzoli V, Ayeni D, Meador CB, Sanganahalli BG, Hyder F, de Stanchina E, Goldberg SB, Pao W and Politi K: Afatinib plus cetuximab delays resistance compared to single-agent erlotinib or afatinib in mouse models of TKI-Naïve EGFR L858R-induced lung adenocarcinoma. Clin Cancer Res 22: 426-435, 2016.

28. Wang Y, Singh R, Wang L, Nilsson M, Goonatilake R, Tong P, Li L, Giri U, Villalobos P, Mino B, et al: Polo-like kinase 1 inhibition diminishes acquired resistance to epidermal growth factor receptor inhibition in non-small cell lung cancer with T790M mutations. Oncotarget 7: 47998-48010, 2016.

29. Leung EL, Fan XX, Wong MP, Jiang ZH, Liu ZQ, Yao XJ, Lu LL, Zhou YL, Yau LF, Tin VP and Liu L: Targeting tyrosine kinase inhibitor-resistant Non-small cell lung cancer by inducing epidermal growth factor receptor degradation via methionine 790 oxidation. Antioxid Redox Signal 24: 263-279, 2016. 